\title{
Ganxiao Dong: A Hotspot of Cave Biodiversity in Northern Guangxi, China
}

\author{
Sunbin Huang ${ }^{1,2}{ }^{\mathbb{D}}$, Guofu Wei ${ }^{3}$, Hengsong Wang ${ }^{4}$, Weixin Liu ${ }^{1, *(\mathbb{D}}$, Anne Bedos ${ }^{5}$, Louis Deharveng ${ }^{5}$ \\ and Mingyi Tian ${ }^{1}$
}

Citation: Huang, S.; Wei, G.; Wang, H.; Liu, W.; Bedos, A.; Deharveng, L.; Tian, M. Ganxiao Dong: A Hotspot of Cave Biodiversity in Northern Guangxi, China. Diversity 2021, 13, 355. https://doi.org/10.3390/ d13080355

Academic Editor:

Spyros Sfenthourakis

Received: 4 June 2021

Accepted: 28 July 2021

Published: 2 August 2021

Publisher's Note: MDPI stays neutral with regard to jurisdictional claims in published maps and institutional affiliations.

Copyright: (C) 2021 by the authors Licensee MDPI, Basel, Switzerland. This article is an open access article distributed under the terms and conditions of the Creative Commons Attribution (CC BY) license (https:/ / creativecommons.org/licenses/by/ $4.0 /)$.
1 Department of Entomology, College of Plant Protection, South China Agricultural University, 483 Wushan Road, Guangzhou 510642, China; huangsunbin@163.com (S.H.); mytian@scau.edu.cn (M.T.)

2 Mécanismes Adaptatifs et Évolution (MECADEV), UMR 7179 CNRS-MNHN, Muséum National d'Histoire Naturelle, CP50, 57 rue Cuvier, 75005 Paris, France

3 Protection Centre of Huanjiang World Natural Heritage, Huanjiang, Hechi 547100, China; tuqinja@163.com

4 School of Karst Science, Guizhou Normal University, 116 Baoshanbeilu, Yunyan, Guiyang 550001, China; wanghengsong796@163.com

5 Institut de Systématique, Évolution, Biodiversité (ISYEB), UMR 7205 CNRS, Muséum National d'Histoire Naturelle, Sorbonne Université, EPHE, 45 rue Buffon, 75005 Paris, France;

bedosanne@yahoo.fr (A.B.); dehar.louis@wanadoo.fr (L.D.)

* Correspondence: da2000wei@163.com

\begin{abstract}
Located in the core zone of Mulun National Nature Reserve in northern Guangxi, the limestone cave Ganxiao Dong harbours the richest cave fauna currently known in China. In total, 26 species of cave invertebrates have been recognized so far, in spite of limited sampling efforts. Of them, 20 are troglobionts or stygobionts, including one snail, four millipedes, three spiders, one harvestman, three isopods, two springtails, two crickets, one non-glowing sticky worm, and three trechine beetles. Six other species are troglophiles. The most remarkable characteristic of this fauna is its high number of troglomorphic species, especially among millipedes, crickets and beetles.
\end{abstract}

Keywords: biodiversity; cave; hotspot; Huanjiang; Guangxi; South China Karst; troglomorphy

\section{Introduction}

The World Heritage Property of South China Karst is a cluster of seven karsts, i.e., Shilin (stone forest) in Yunnan, Shibing and Maolan in Guizhou, Jinfoshan and Wulong in Chongqing, as well as Guilin and Huanjiang in Guangxi (https:/ / whc.unesco.org/ en/list/1248/, accessed on 1 July 2021). The Huanjiang Karst component is located in the Guangxi Zhuang Autonomous Region within the boundaries of the Mulun National Nature Reserve. Actually, Maolan and Mulun are the same karst unit across the border between Guizhou and Guangxi, and the karst unit is totally included in national nature reserves. The Huanjiang karst is a large Fengcong (peak cluster) landscape covered with primary forest and hundreds of scattered caves. The cave biodiversity in this karst has been recently investigated and shown to be very rich [1-3]. The cave which will be dealt with in this paper, Ganxiao Dong, is located in the Mulun karst.

The Huanjiang Karst World Natural Heritage Site is located in Huanjiang Maonan Autonomous County, northern Guangxi, with a total area of $115.59 \mathrm{~km}^{2}$. The area is a typical tropical-subtropical karst landscape with the main landform of so-called peakcluster depression (Figure 1), as well as other landforms, for example, dolines, fossil valleys and cave systems. Geographically, Huanjiang Karst belongs to the slope zone from the Yunnan-Guizhou plateau to the hilly basin of Guangxi, decreasing in elevation from $1028 \mathrm{~m}$ a.s.l. in the northwest to $250 \mathrm{~m}$ a.s.l. in the southeast. The topography of the area is fragmented due to the erosion-denudation of the eastern Gubin River and the western Dagou River and the fault structure in the area, making it a typical area for the development of conical peak-cluster karst landforms in the mid-subtropical zone $[4,5]$. 


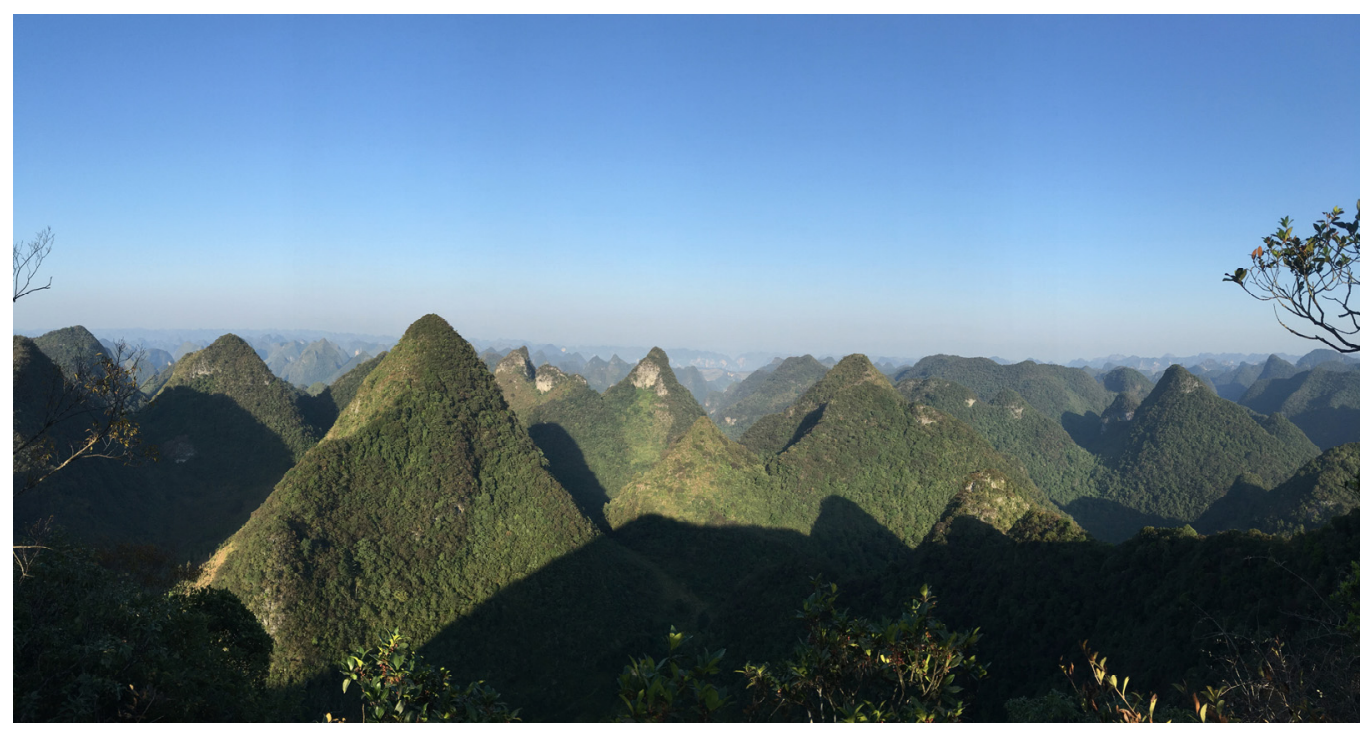

Figure 1. Fengcong peak cluster landscapes in Huanjiang Karst, Hechi, Guangxi, China.

Forest coverage exceeds $95 \%$ and predominantly is comprised of a mixed evergreen and deciduous broad-leaved forest. The humid subtropical climate, the diverse karst habitats and the enclosed island-like environment are conducive to the growth and reproduction of living organisms. Likewise, there are hundreds of limestone caves distributed in this area, such as Cave Ganxiao Dong, Cave Dongtu Dong, Cave Mashan Dong and so on.

$\mathrm{Xu}$ Xiake, the first karstologist and caver of China (1587-1641), explored or located more than 270 caves in Guangxi. After this pioneering work, nothing significant was published on the karst of China for about 300 years. Modern cave exploration and karstology developed rapidly from the 1970s onwards, first through many foreign expeditions, then through increasing efforts of Chinese cavers. Speleologically, the most impressive result of this activity is the exploration of the Shuanghe cave system in Guizhou, today the largest in China and Asia with over $300 \mathrm{~km}$ of passages (Jean Botazzi, pers. comm.)

Research on cave biology in Chinese caves began in 1960 with the description of five millipedes and one centipede by Loksa [6], followed in 1981 by that of the cave fish Oreonectes anophthalmus, described by Zheng, the first of a long series. The first cave beetle was described in 1991 (Sinaphaenops mirabilissimus Uéno \& Wang, 1991), the first cave Collembola in 1993 (Sinella trogla Chen \& Christiansen, 1993) and the first cave woodlice in 1995 (Sinoniscus cavernicolus Schultz 1995). All these animals were collected in the caves of Guangxi or Guizhou, but none of them is from the Mulun karst.

These zoological groups, fish, millipedes, woodlice, springtails and beetles, together with spiders, represent today the bulk of the cave diversity of Chinese caves, with tens of new species described since then. Three of these groups have been particularly studied in the Mulun karst: millipedes, woodlice and beetles.

Millipedes are the most common terrestrial medium- to large-size invertebrates in the caves of South China Karst [7]. However, the diversity of cave millipedes in China has been revealed and recognized only during the last few decades. Approximately 350 millipede species from China have been named at present, including at least a third only known from caves [8]. In Mulun, the first cave millipede, Eutrichodesmus similis, reported by Golovatch et al., 2009, was described from Gui Dong and Shenlong Dong. Since this date, 16 species of Diplopoda have been reported from this karst [8].

Oniscid isopods are the only crustaceans that are fully adapted to terrestrial habitats, mostly living in wet and often dark environments. Cave-dwelling isopods are common in southern China. Most of them are terrestrial, but a few species have returned to aquatic life [9]. Contrary to millipedes and beetles, they are represented by few genera in Chinese caves, of which Dryadillo is found in many provinces in China, including troglobiotic 
and troglophilic species, while Trogloniscus is endemic to southern Guizhou and northern Guangxi, with five troglobiotic or stygobiotic species.

South China (northern Guangxi and southern Guizhou) is the world hot-spot for cave Trechinae beetles, having recently overpassed the historical hotspots of the Pyrenees and Dinarides in the number of taxa and levels of troglomorphy [10]. They are diversified in many genera and species, and all narrowly endemic, including the most impressive troglomorphic beetles known so far [10]. The first troglobiotic trechine species reported in China, Sinaphaenops mirabilissimus, by Uéno \& Wang, 1991, was discovered in a show cave in Maolan, Libo County of southern Guizhou, which is adjacent to the Mulun Reserve [11]. Subsequently, Uéno \& Ran [12] reported two other species from this county: S. gracilior from Cave Shui Dong, and S. wangorum from Cave Lasuo Dong in 1998. The latter also expands into northern Guangxi, occurring in several caves of the Mulun karst of Huanjiang County [13]. Similarly, Libotrechus nishikawai, described by Uéno, 1998, and Uenotrechus liboensis, described by Deuve \& Tian, 1999, were formerly found in Maolan [14,15], then collected in Mulun. In addition, U. gejianbangi, described by Tian \& Wei, 2017, was only found from the cave Ji Dong (also called Shuiku Dong) in Mulun. The genus Pilosaphaenops, reported by Deuve \& Tian, 2008, contains six species, of which four are distributed in the Maolan-Mulun karst: P. hybridiformis (Uéno, 2002) from Maolan, P. pilosulus (Deuve \& Tian 2008), P. whitteni Tian, 2011 and P. weiguofui Huang et al., 2020 from Mulun and related karsts near Sancai and Dacai (Huanjiang). For the genus Oodinotrechus, reported on by Uéno, 1998, two species were reported from this area, O. kishimotoi Uéno, 1998 from a cave in Maolan and O. liyoubangi Tian, 2014 from three caves in Mulun. The Maolan-Mulun karst is therefore home to 12 cave Trechinae, and several of them are highly troglomorphic.

This paper is the first contribution dedicated to Ganxiao Dong. This cave has the richest cave fauna of the Mulun-Maolan karst and of China, according to the surveys we have conducted for 10 years, as well as Mulun being itself the richest region of China for subterranean fauna [1].

\section{Materials and Methods}

\subsection{Research Site}

The cave Ganxiao Dong is close to the provincial border between Guizhou and Guangxi (Figure 2A), in the core zone of the adjacent Maolan and Mulun National Nature Reserves, both World Natural Heritage Sites of South China Karst. The cave is located in the northwest of Xiazhai Village, Chuanshan Town, Huanjiang County $\left(25^{\circ} 10^{\prime} 57^{\prime \prime} \mathrm{N}\right.$, $108^{\circ} 01^{\prime} 55^{\prime \prime} \mathrm{E}$ ). It is a medium-sized cave ( $836 \mathrm{~m}$ in total length), with pools of water and various terrestrial subterranean habitats favourable for subterranean species and invertebrate communities (Figure 2B).

The main entrance (Figure 3A) of Ganxiao Dong is $16 \mathrm{~km}$ away from Chuanshan Town in a straight-line distance, at an altitude of $735 \mathrm{~m}$. The total length of the cave is $836 \mathrm{~m}$, of which the main gallery is $620 \mathrm{~m}$ and the branch length is $216 \mathrm{~m}$. The highest point in the main gallery is $48 \mathrm{~m}$ and the widest section is $26 \mathrm{~m}$. There are two branches after the first part of the main gallery: the western branch is a dry passage in a higher position, with a length of $73 \mathrm{~m}$; the eastern branch is longer $(143 \mathrm{~m})$. The entrance is $20 \mathrm{~m}$ wide and $9 \mathrm{~m}$ high, orientated at $335^{\circ} \mathrm{N}$ with a $15-20^{\circ}$ downward slope. Two additional cave entrances are also opened on the northern side of the hill, at the level of the western branch. Both entrances are small, accessible only by a person at the same time. Five chambers (Figure 3B) exist inside the cave.

Influenced by the fracture and the strata altitude, the cave is overall nearly north-south oriented, with many bifurcations, and most of the sub-sections facing north-west or southeast. The cave plan is " $Y$ " shaped and extends in a right-angle bend. In the longitudinal section, the main gallery extends in a north-south upward direction, ending on a collapse of stones. Due to gravity, the roof collapsed, and formed a vaulted chamber. The main gallery of the cave is spacious, while the branches are narrower. The bottom of the cave is uneven and the ceiling obviously collapsed, which caused the development of ridges and 
conchoidal fractures. At the bottom of the main gallery, several depressions were found, one of them being a $1 \mathrm{~m}$ deep and $10 \mathrm{~m}^{2}$ areal pool (Figure 3C). Cross-sections of cave galleries are mainly triangular, sub-triangular or trapezoidal, mostly of large size (one to $47 \mathrm{~m}$ wide and two to $30 \mathrm{~m}$ high).

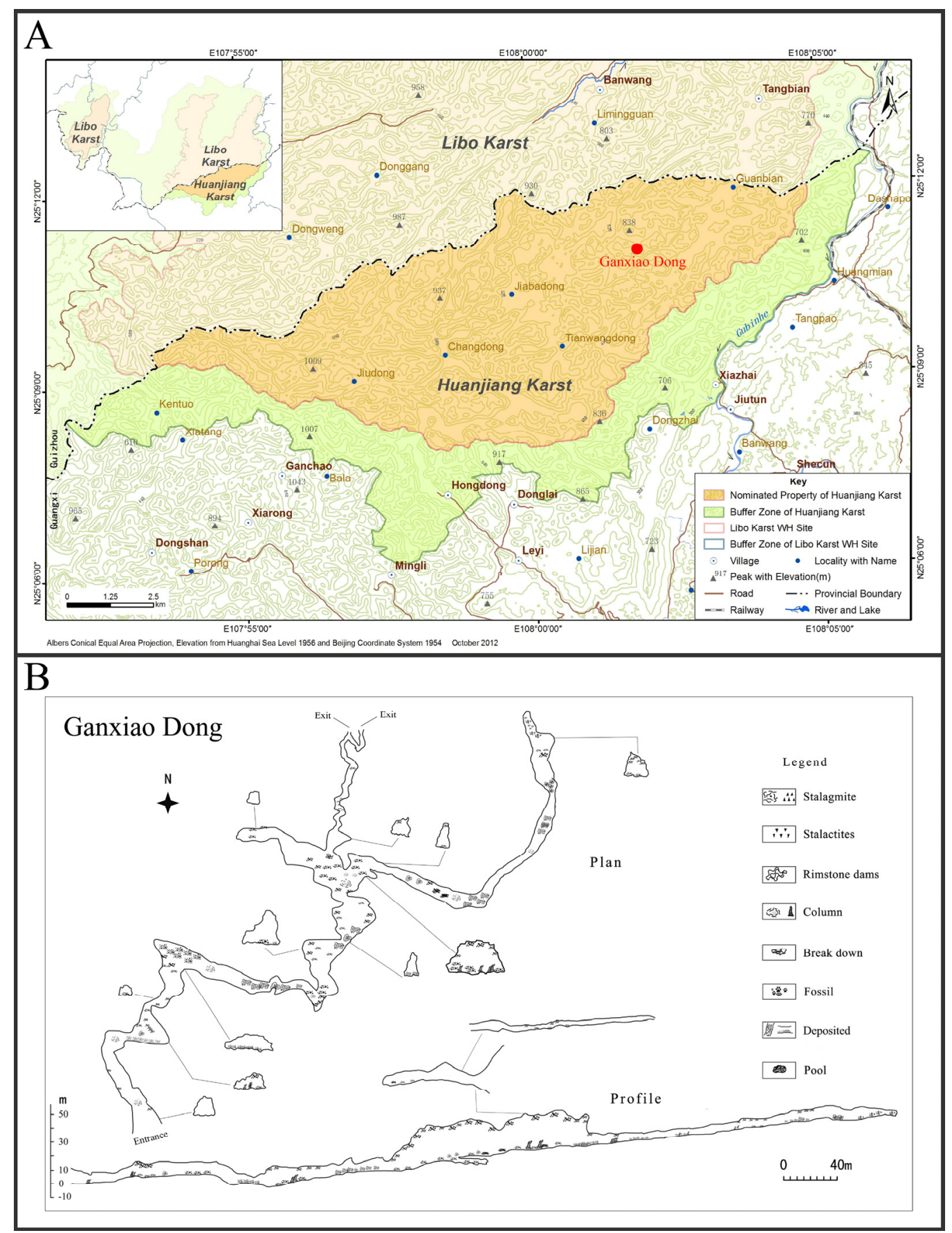

Figure 2. Location of Ganxiao Dong (A) and map of the cave (B).

The speleothems formed inside the cave are very diverse, including in particular stalagmites, stalactites, stone columns, stone mushrooms, stone curtains, stone shields, stone rimstone dams and stone pearls (Figure 3D-F). They are mainly distributed in the main gallery and the eastern branch, while the western branch has very few speleothems inside the passage because it is a high-level dry cave. Stone mushrooms, stone curtains and stone shields are only found in the main gallery, while the rimstone dams and stone 
pearls are only found in the eastern branch. The mechanical deposits in the cave are mainly sediments, with a few biological deposits such as bat guano.
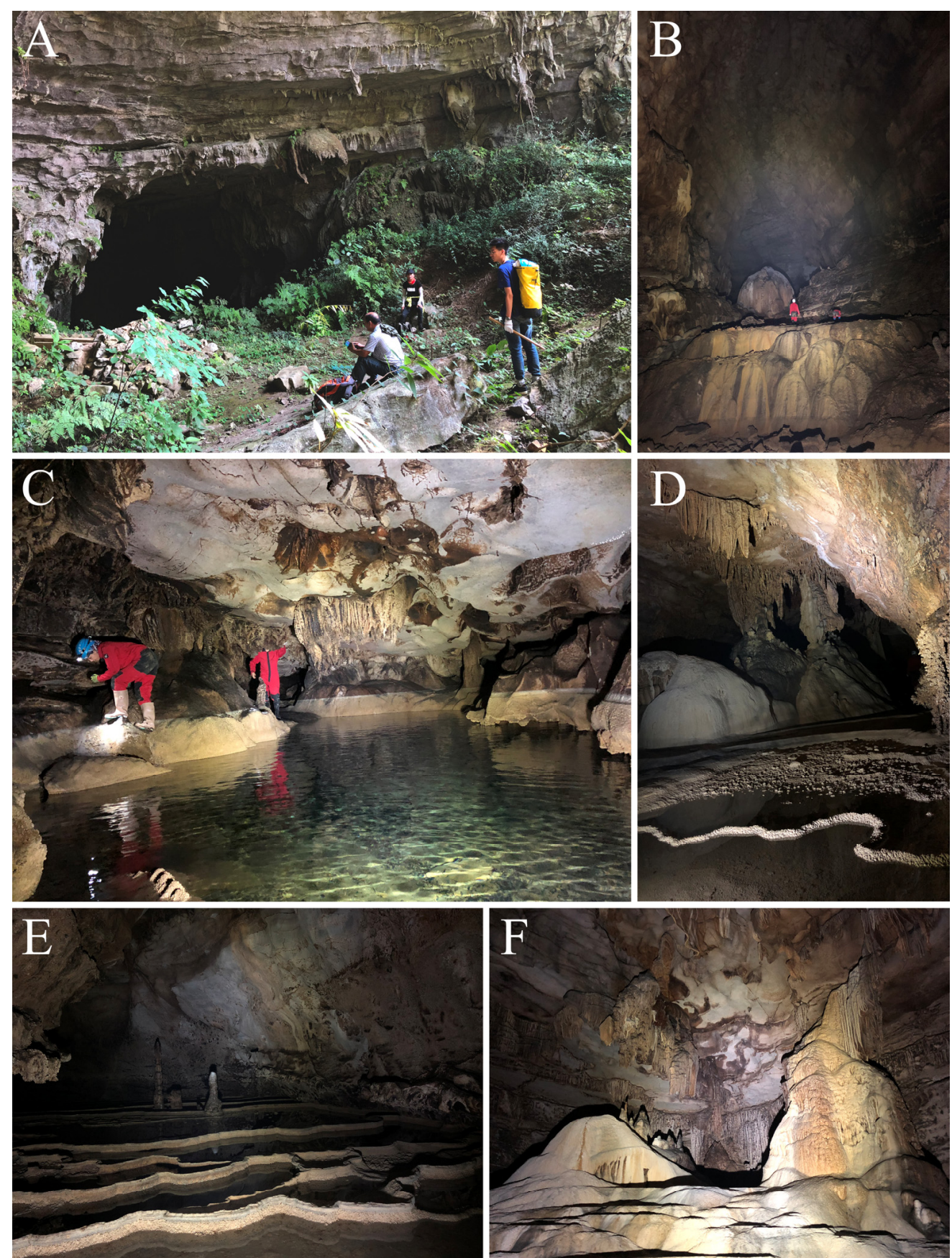

Figure 3. Geomorphological characteristics of Ganxiao Dong. (A) entrance; (B) large chamber; (C) pool; (D-F) stalactites, rimstone dams, stalagmites and columns.

\subsection{Sampling}

Six biological surveys were conducted in the cave Ganxiao Dong during different seasons from 2009 to 2019. Collections were made by hand or using an aspirator and kept in $75 \%$ ethanol for morphological studies and identification or $95 \%$ ethanol for DNA sequencing and molecular analyses. Photos of the cave animals were taken by a Canon EOS 6D camera (Tokyo, Japan) with a Canon EF 100mm f/2.8L IS USM lens (Tokyo, Japan) and an adapted Meike MK-14 ext E-TTL macro flash (Hongkong, China). They were then processed using Photoshop CC 2019 (San Jose, CA, USA). 
All materials studied are deposited in the animal collections of South China Agricultural University.

\subsection{Terminology}

Cave terrestrial animals are generally divided into three ecological categories based on their adaptation to cave life: troglobionts, troglophiles and trogloxenes [16]. Similarly, aquatic cave animals are referred to as stygobionts, stygophiles and stygoxenes. Troglobionts are fully adapted to the cave environment and are unable to survive outside the cave. Most of them are lacking in pigments, without eyes or visual organs. Troglophiles have populations in the dark cave environment but also outside (eutroglophiles) or are linked to caves only for a part of their life cycle (subtroglophiles). Trogloxenes enter the cave accidentally [17]. Troglomorphy, i.e., a set of morphological traits assumed to be linked to cave life, is the most spectacular characteristic of many cave invertebrates of South China karsts. It includes eye regression, winglessness and depigmentation, three traits observed as well in soil invertebrates, associated with body size increase and appendage elongation [18].

\section{Results}

\subsection{Cave Fauna Composition}

In total, 26 cave invertebrates have been discovered in Ganxiao Dong, including 19 troglobiotic, one stygobiotic and six troglophilic species (Table 1).

Table 1. Species list of cave-adapted animals from cave Ganxiao Dong. Column status: $\mathrm{Tb}=$ troglobiont; $\mathrm{Tp}=$ troglophile; $\mathrm{Sb}=$ stygobiont; $^{*}=$ known endemic of the Maolan-Mulun karst or of Ganxiao Dong; ? = not sure or under study.

\begin{tabular}{|c|c|c|c|c|c|}
\hline No. & Species & Family & Order & Class & Status \\
\hline 1 & Sinospelaeobdella sp. & Haemadipsidae & Gnathobdellida & Hirudinea & $\mathrm{Tp}$ \\
\hline 2 & Euplecta sp. & Ariophatidae & Stylommatophora & Gastropoda & $\mathrm{Tb}$ \\
\hline 3 & Chalepotaxis sp. & Helicarionidae & Stylommatophora & Gastropoda & $\mathrm{Tp}$ \\
\hline 4 & $\begin{array}{l}\text { Hyleoglomeris kunnan Golovatch, Liu \& Geoffroy, } \\
\qquad 2012\end{array}$ & Glomeridae & Glomerida & Diplopoda & $\mathrm{Tb}^{*}$ \\
\hline 5 & $\begin{array}{l}\text { Eutrichodesmus similis Golovatch, Geoffroy, } \\
\text { Mauries \& VandenSpiegel, } 2009\end{array}$ & Haplodesmidae & Polydesmida & Diplopoda & $\mathrm{Tb}^{*}$ \\
\hline 6 & $\begin{array}{c}\text { Pacidesmus bedosae Golovatch, Geoffroy \& } \\
\text { Mauries, } 2010\end{array}$ & Polydesmidae & Polydesmida & Diplopoda & $\mathrm{Tb}^{*}$ \\
\hline 7 & $\begin{array}{l}\text { Glyphiulus proximus Golovatch, Geoffroy, } \\
\text { Mauries \& VandenSpiegel, } 2011\end{array}$ & Cambalopsidae & Spirostreptida & Diplopoda & $\mathrm{Tb}^{*}$ \\
\hline 8 & Epedanidae sp. & Epedanidae & Opiliones & Arachnida & $\mathrm{Tb}$ \\
\hline 9 & Troglocoelotes proximus (Chen, Zhu \& Kim, 2008) & Agelenidae & Araneae & Arachnida & $\mathrm{Tb}^{*}$ \\
\hline 10 & Speleoticus libo (Chen \& Zhu, 2005) & Nesticidae & Araneae & Arachnida & $\mathrm{Tb}^{*}$ \\
\hline 11 & Telema sp. & Telemidae & Araneae & Arachnida & $\mathrm{Tb}$ \\
\hline 12 & Sparassidae sp. & Sparassidae & Araneae & Arachnida & $\mathrm{Tp}$ \\
\hline 13 & Trogloniscus trilobatus Taiti \& Xue, 2012 & Styloniscidae & Isopoda & Crustacea & $\mathrm{Sb}^{*}$ \\
\hline 14 & Trogloniscus deharvengi Taiti \& Xue, 2012 & Styloniscidae & Isopoda & Crustacea & $\mathrm{Tb}^{*}$ \\
\hline 15 & Dryadillo sp. & Armadillidae & Isopoda & Crustacea & $\mathrm{Tb}$ \\
\hline 16 & Sinella sp. & Entomobryidae & Entomobryomorpha & Collembola & $\mathrm{Tb}$ \\
\hline 17 & Coecobrya sp. & Entomobryidae & Entomobryomorpha & Collembola & $\mathrm{Tb}$ \\
\hline 18 & Sarasaeschna sp. & Aeshnidae & Odonata & Insecta & $\mathrm{Tp} ?$ \\
\hline 19 & $\begin{array}{l}\text { Tachycines (Gymnaeta) ferecaecus (Gorochov, } \\
\text { Rampini \& Di Russo, 2006) }\end{array}$ & Rhaphidophoridae & Orthoptera & Insecta & $\mathrm{Tb}^{*}$ \\
\hline 20 & Tachycines (Gymnaeta) sp.1 & Rhaphidophoridae & Orthoptera & Insecta & $\mathrm{Tp}$ \\
\hline 21 & Tachycines (Gymnaeta) sp.2 & Rhaphidophoridae & Orthoptera & Insecta & $\mathrm{Tb}$ \\
\hline 22 & Chetoneura sp. & Keroplatidae & Diptera & Insecta & $\mathrm{Tb}$ \\
\hline 23 & Libotrechus nishikawai Uéno, 1998 & Carabidae & Coleoptera & Insecta & $\mathrm{Tb}^{*}$ \\
\hline 24 & Sinaphaenops wangorum Uéno \& Ran, 1998 & Carabidae & Coleoptera & Insecta & $\mathrm{Tb}^{*}$ \\
\hline 25 & Pilosaphaenops hybridiformis (Uéno, 2002) & Carabidae & Coleoptera & Insecta & $\mathrm{Tb}^{*}$ \\
\hline 26 & Micronemadus pusillimus (Kraatz, 1877) & Leiodidae & Coleoptera & Insecta & $\mathrm{Tp}$ \\
\hline
\end{tabular}




\subsection{Notes on Cave Animals Living in Cave Ganxiao Dong}

\subsubsection{Leech}

Sinospelaeobdella sp. occurs in Ganxiao Dong, wandering on roofs or walls (Figure 4A). Its two species, distributed in tropical continental Asia (China, Laos and Myanmar), are given in the literature as sucking the blood of different bat species, including Rhinolophus pearsonii Horsfield, 1851 which is present in the cave [19].
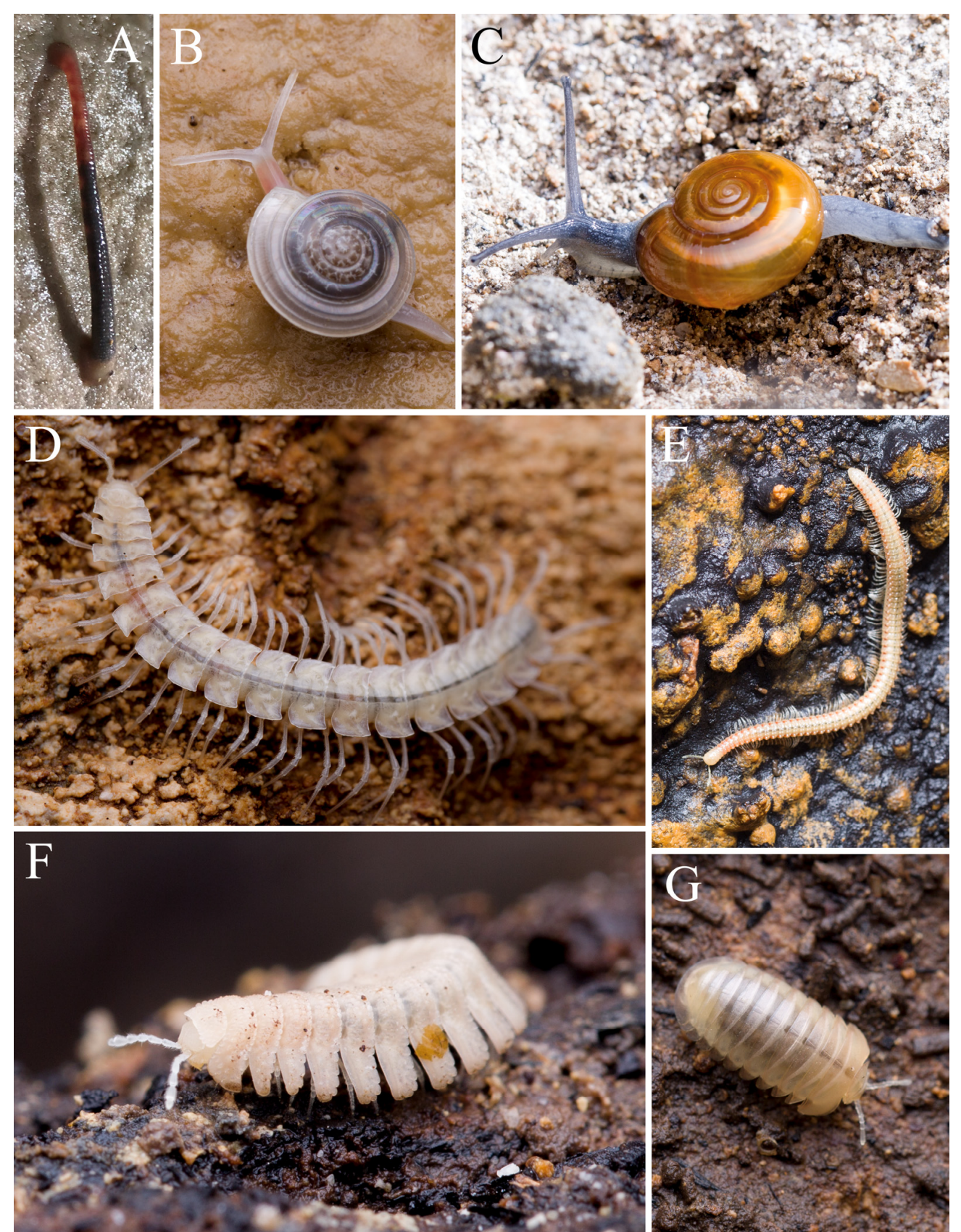

Figure 4. Cave animals in Ganxiao Dong: (A) leech Sinospelaeobdella sp.; (B) snail Euplecta sp. and (C) snail Chalepotaxis sp.; (D) Pacidesmus bedosae Golovatch et al., 2010; (E) Glyphiulus proximus Golovatch et al., 2011; (F) Eutrichodesmus similis Golovatch et al., 2009; (G) Hyleoglomeris kunnan Golovatch et al., 2012.

\subsubsection{Snails}

Two species of terrestrial snails are living inside Ganxiao Dong. Among them, Euplecta sp. (Figure 4B) is likely a troglobiont, while Chalepotaxis sp. (Figure 4C) is a troglophile. 


\subsubsection{Millipedes}

Four millipede species of four different genera, families and orders, have been discovered in Ganxiao Dong [8]: Pacidesmus bedosae (Polydesmidae, Polydesmida) (Figure 4D), Glyphiulus proximus (Cambalopsidae, Spirostreptida) (Figure 4E), Eutrichodesmus similis (Haplodesmidae, Polydesmida)(Figure 4F) and Hyleoglomeris kunnan (Glomeridae, Glomerida) (Figure 4G). In China, the genus Glyphiulus is the richest among millipedes (43 species), followed by Hyleoglomeris (32 species) and Eutrichodesmus (24 species). All three genera, represented in China by many troglobionts that are moderately troglomorphic, are common in Ganxiao Dong, as well as in many caves of Mulun. The oligospecific genus Pacidesmus is less common in caves, but it encompasses impressive troglomorphic troglobionts, like $P$. bedosae of Ganxiao Dong with very long antennae and legs. The co-occurrence of several troglobiotic millipede species in this cave is not unusual. In Mulun, up to 6 unambiguously troglobiotic and often troglomorphic species may be found in a same cave [1]. Actually, Diplopoda represents the most diversified invertebrate group of the Mulun karst with 16 troglobionts recorded so far, a richness unmatched anywhere else in the world [8].

\subsubsection{Harvestman}

Only an unidentified harvestman species lives in Ganxiao Dong, belonging to the family Epedanidae (Figure 5A). It is omnivorous and considered to be a troglobiont due to noticeable depigmentation.

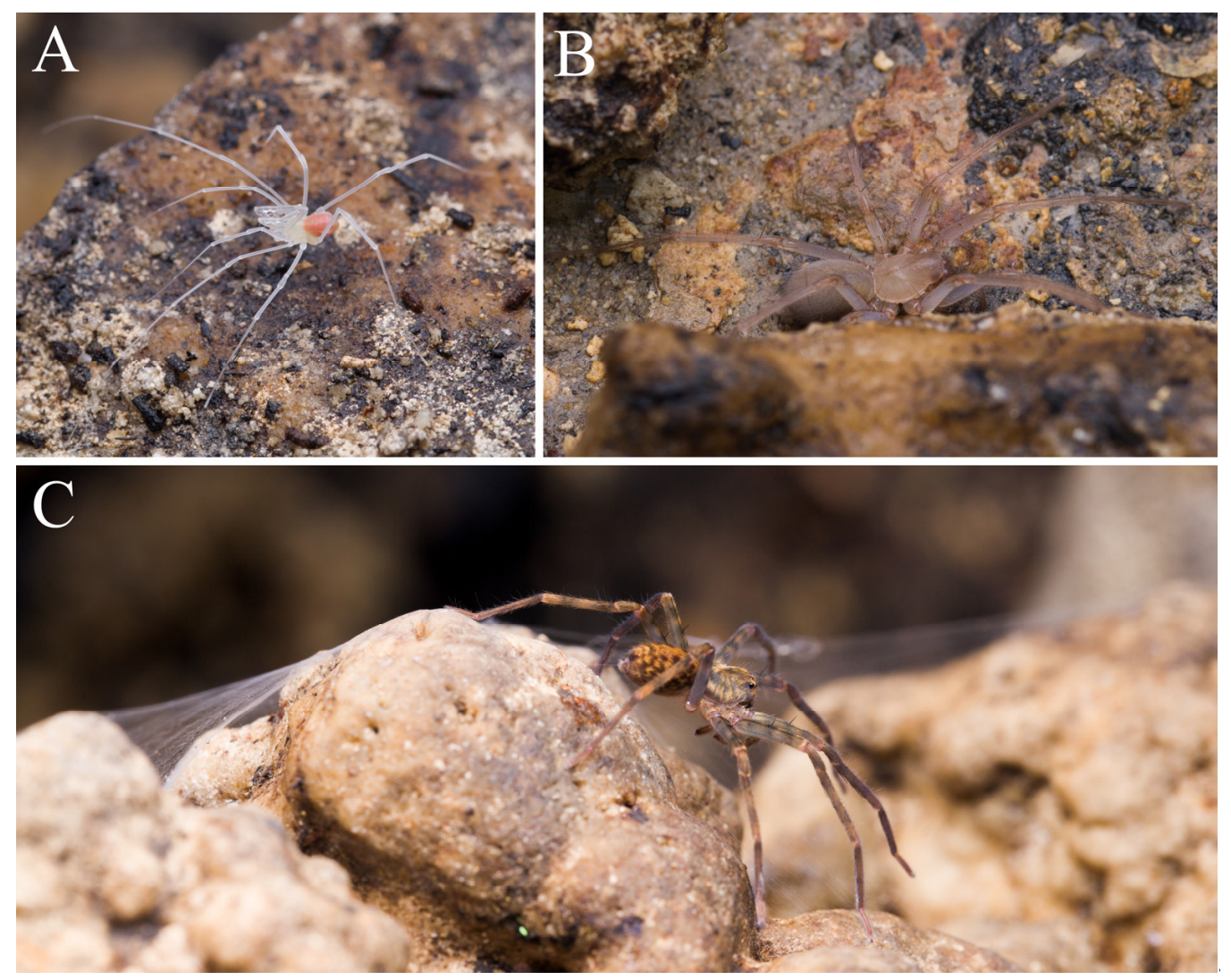

Figure 5. Harvestman and spiders in Ganxiao Dong. (A) Epedanidae sp.; (B) Troglocoelotes proximus (Chen, Zhu \& Kim, 2008); (C) Sparassidae sp.

\subsubsection{Spiders}

Four spider species are found in Ganxiao Dong. Three of them, namely Troglocoelotes proximus (Figure 5B), Speleoticus libo and Telema sp. are troglobiotic. An unidentified species of Sparassidae, a troglophile, is also found inside this cave (Figure 5C). 


\subsubsection{Woodlice}

Three species of troglobiotic woodlice (Isopoda) occur inside Ganxiao Dong. The genus Trogloniscus has two species, blind and depigmented, of which one, T. trilobatus is a stygobiont (Figure 6A) and the other one, T. deharvengi, is a troglobiont (Figure 6B) (Taiti $\&$ Xue, 2012). These two species are very similar in habitus, but easily distinguished on small somatic characters. It is very unusal to have, in a same well defined genus, species with such different ecological life styles, especially because both are abundant in the cave. Further investigations on the ecology of these species are clearly needed; in particular, the aquatic could be amphibious, like it happens in other Styloniscidae of SE Asia. The third species, Dryadillo sp. (Figure 6C) is also a troglobiont but has some remains of eyes. All three species are saprophagous and rather abundant in the cave.
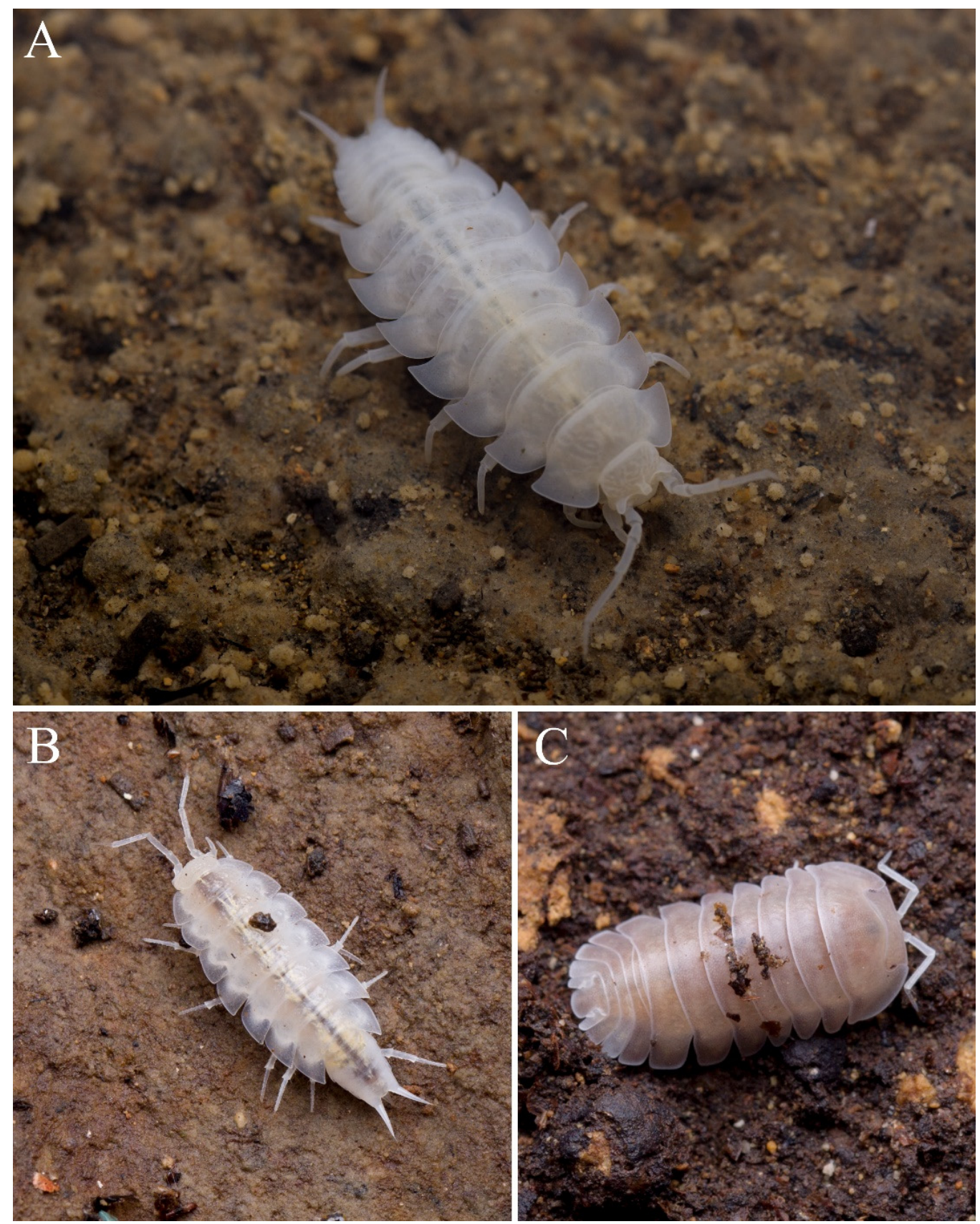

Figure 6. Woodlice in Ganxiao Dong. (A) Trogloniscus trilobatus Taiti \& Xue, 2012; (B) Trogloniscus deharvengi Taiti \& Xue, 2012; (C) Dryadillo sp. 


\subsubsection{Springtails}

Two springtails (Collembola), Sinella sp. and Coecobrya sp., occur in sympatry within Ganxiao Dong. They are small, whitish and good at jumping, feeding on dead wood, litter, or animal dung in the cave. Springtails play an important role in the cave food chain as they are the prey to many predators such as ground beetles and spiders. The two genera have several troglobionts and surface species, mostly undescribed, and are often abundant in caves of Mulun and China. Morphologically, they exhibit various degrees of troglomorphy, up to extreme appendage elongation.

\subsubsection{Dragonfly}

An unexpected discovery was a larva of the dragonfly Sarasaeschna sp. (Aeshnidae, Figure 7A), collected in a pool far inside the cave, suggesting some links to the cave environment (possibly troglophily) and currently under study (Haomiao Zhang, pers. comm.).
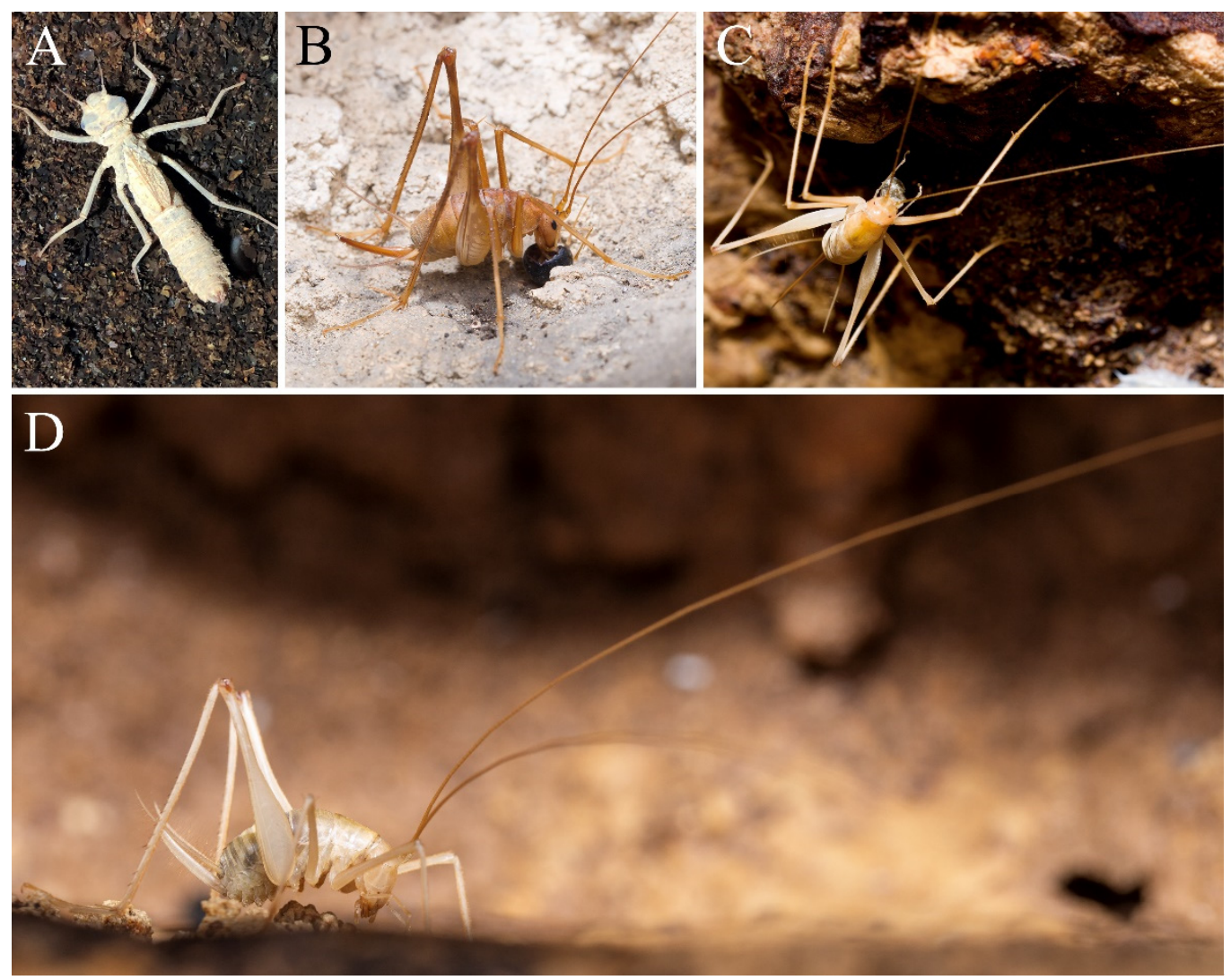

Figure 7. Dragonfly and crickets in Ganxiao Dong. (A) Nymph of Sarasaeschna sp.; (B) Tachycines (Gymnaeta) sp.1; (C) Tachycines (Gymnaeta) ferecaecus (Gorochov, Rampini \& Di Russo, 2006); (D) Tachycines (Gymnaeta) sp.2.

\subsubsection{Crickets}

Three species of cave crickets (Rhaphidophoridae) are living in Ganxiao Dong. This remarkable diversity is not exceptional in southern China karst, where two and sometimes three species of Rhaphidophoridae may co-occur. It is the case in the Parking cave of Huoyan (Longshan in Hunan province) which hosts Tachycines (Gymnaeta) omninocaecus (Gorochov et al., 2006), T. (G.) solidus (Gorochov et al., 2006) and Eutachycines crenatus (Gorochov et al., 2006), each species occupying a different section of the cave with limited spatial overlap (Gorochov et al., 2006 and unpublished data). Among the Ganxiao Dong crickets, two are troglobionts with depigmented bodies: Tachycines (Gymnaeta) ferecaecus with very reduced eyes (Figure 7C), originally described from a cave in Maolan, and the blind species illustrated in Figure 7D. The third species, T. (G.) sp.1 (Figure 7B), has 
medium-size eyes and a coloured body, and is likely a troglophile. The three species have no wings, but well-developed jumping legs and are omnivorous, feeding on bat guano, fungi or preying on other small invertebrates.

\subsubsection{Non-Glowing Sticky Worm}

One species of non-glowing sticky worm, Chetoneura sp. (Figure 8A), occurs in Ganxiao Dong. Chetoneura catches their prey by means of a special curtain-like trap which is composed of threads with dew sticked by the worms (Figure 8B,C). A recent biological study [20] shows that Chetoneura shennonggongensis Amorim \& Niu 2008, described from China, may spend its entire life within the cave, as adults have a very short life span, do not feed and have very limited flying ability. Therefore, in spite of the large size of their eyes, they can be considered as troglobionts. Chetoneura, the only genus of fungus gnats known to develop in caves, has only two described species in the oriental region, but unidentified non-glowing sticky worms are common in many caves of the oriental region, and may uncover a larger taxonomic diversity.
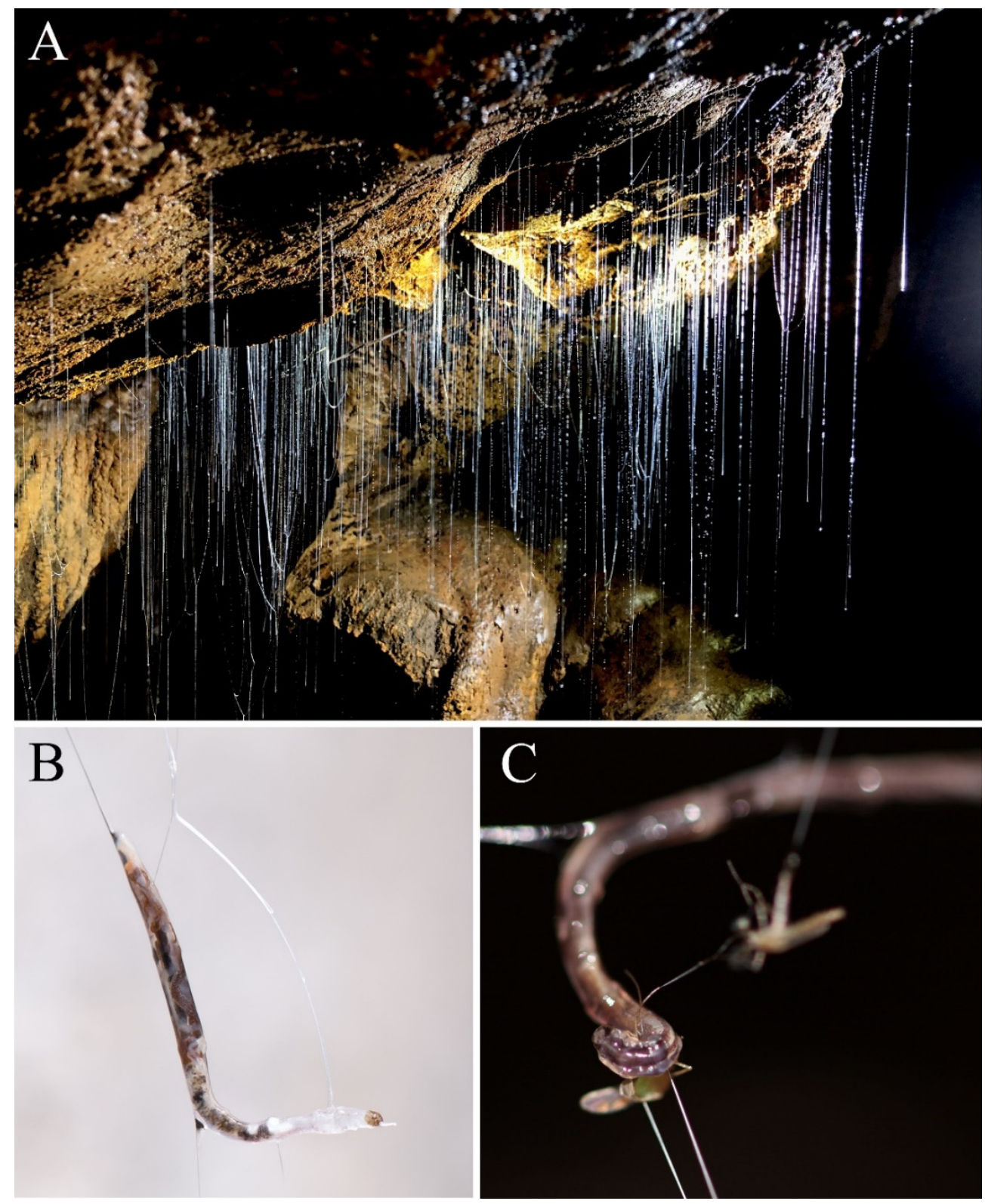

Figure 8. Non-glowing sticky worms (larvae of Keroplatidae) in Ganxiao Dong. (A) a cluster of larvae and threads; (B) a larva; (C) a larva feeding on a mosquito. 


\subsubsection{Ground Beetles}

Three species of troglobiotic ground beetles (Carabidae) are living in Ganxiao Dong, i.e., Pilosaphaenops hybridiformis (Figure 9A), Sinaphaenops wangorum (Figure 9B), and Libotrechus nishikawai (Figure 9C) (Tian 2010 and unpublished). All of them belong to the subfamily Trechinae, and are anophthalmic. The last one is not strongly modified, whereas the other two are aphaenopsian, with elongated body and appendages, and modified mouthparts. They are predators, feeding on springtails (pers. obs.) or even probably eggs of other invertebrates, and are present in most caves of the region. All of them are narrowly endemic [10].

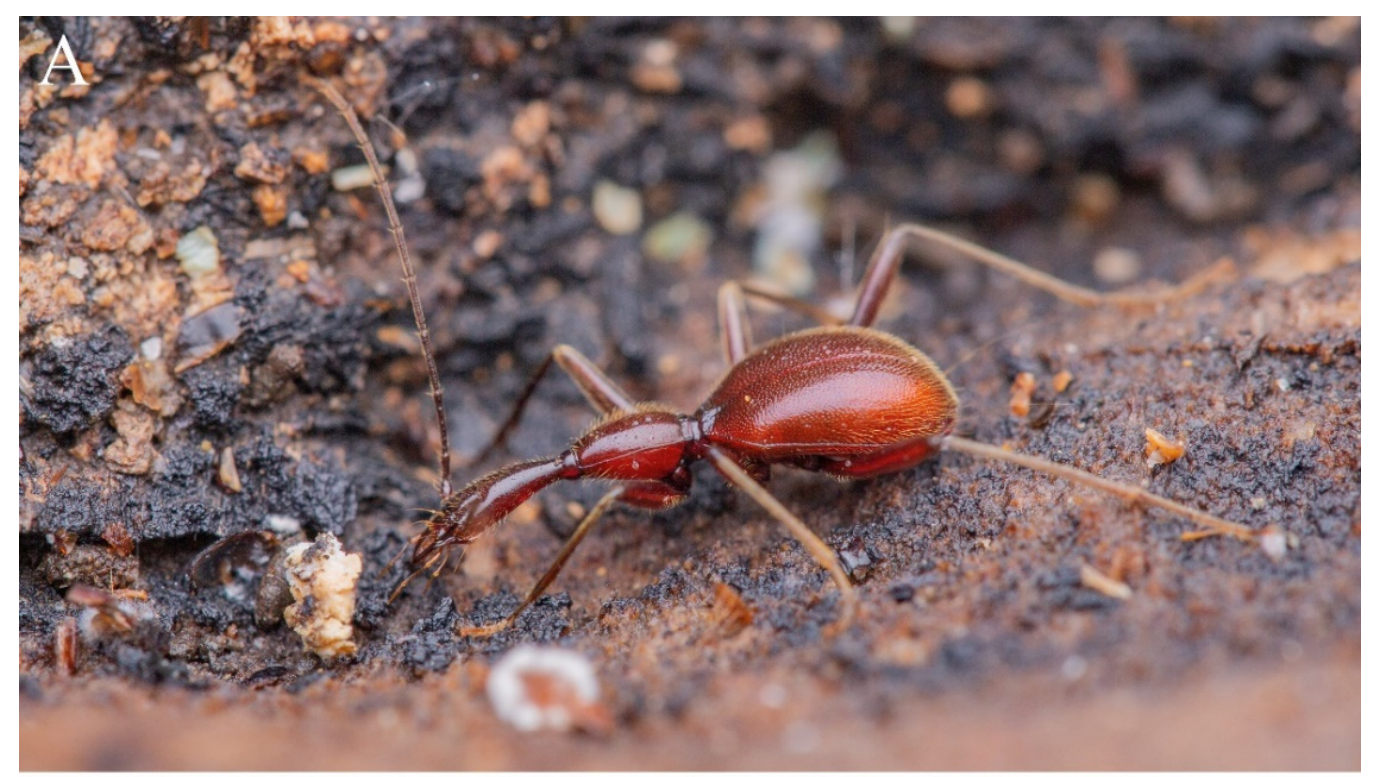

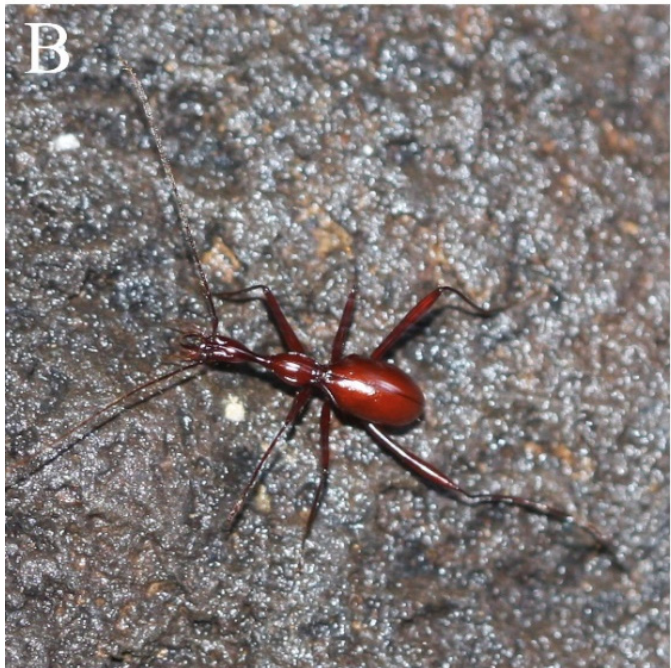

Figure 9. Ground beetles in Ganxiao Dong

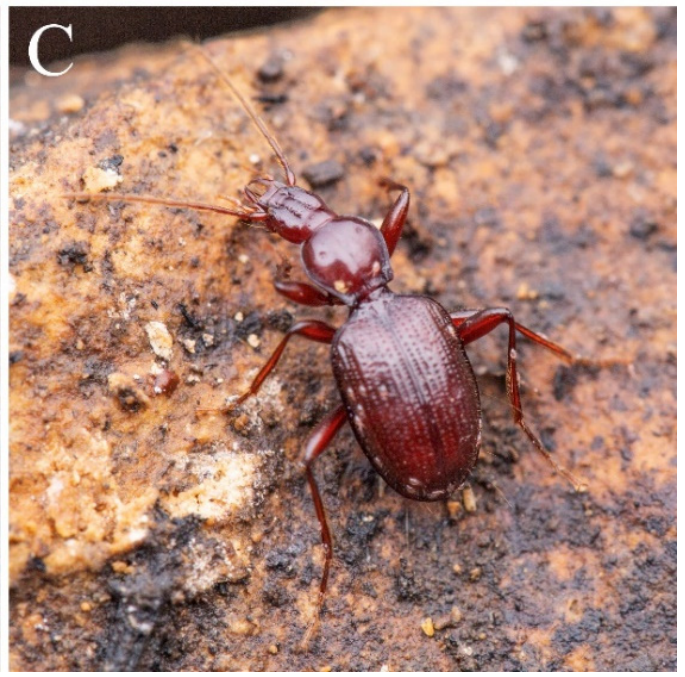

(A) Pilosaphaenops hybridiformis (Uéno, 2002); (B) Sinaphaenops wangorum Uéno \& Ran, 1998; (C) Libotrechus nishikawai Uéno, 1998.

\subsubsection{Round Fungus Beetles}

One species of round fungus beetles, Micronemadus pusillimus (Kraatz, 1877) (Leiodidae), was found in Ganxiao Dong. This species is similar in morphology to its surface relatives, and is considered as a troglophile. It is widespread, found in Mashan Dong from the same karst [2] and reported also in Malaysia, Indonesia, Japan [21]. 


\subsubsection{Vertebrates}

Although they are not cited in Table 1, bats are nevertheless very common mammals in Chinese caves, at the basis of the food webs, because of their guano and carcasses which represent food sources for micro-organisms and saprophagous invertebrates. In Ganxiao Dong only Rhinolophus pearsonii (Figure 10A) was observed. The species is widespread in southern continental Asia, listed in the IUCN Red List of Threatened Species as Least Concerned. It generally lives in groups from a dozen to several dozens, hanging on rock walls or cave ceilings. It is a food source of the parasite Sinospelaeobdella, a jawed land leech which is present in that cave, though it was not observed on the bat itself.
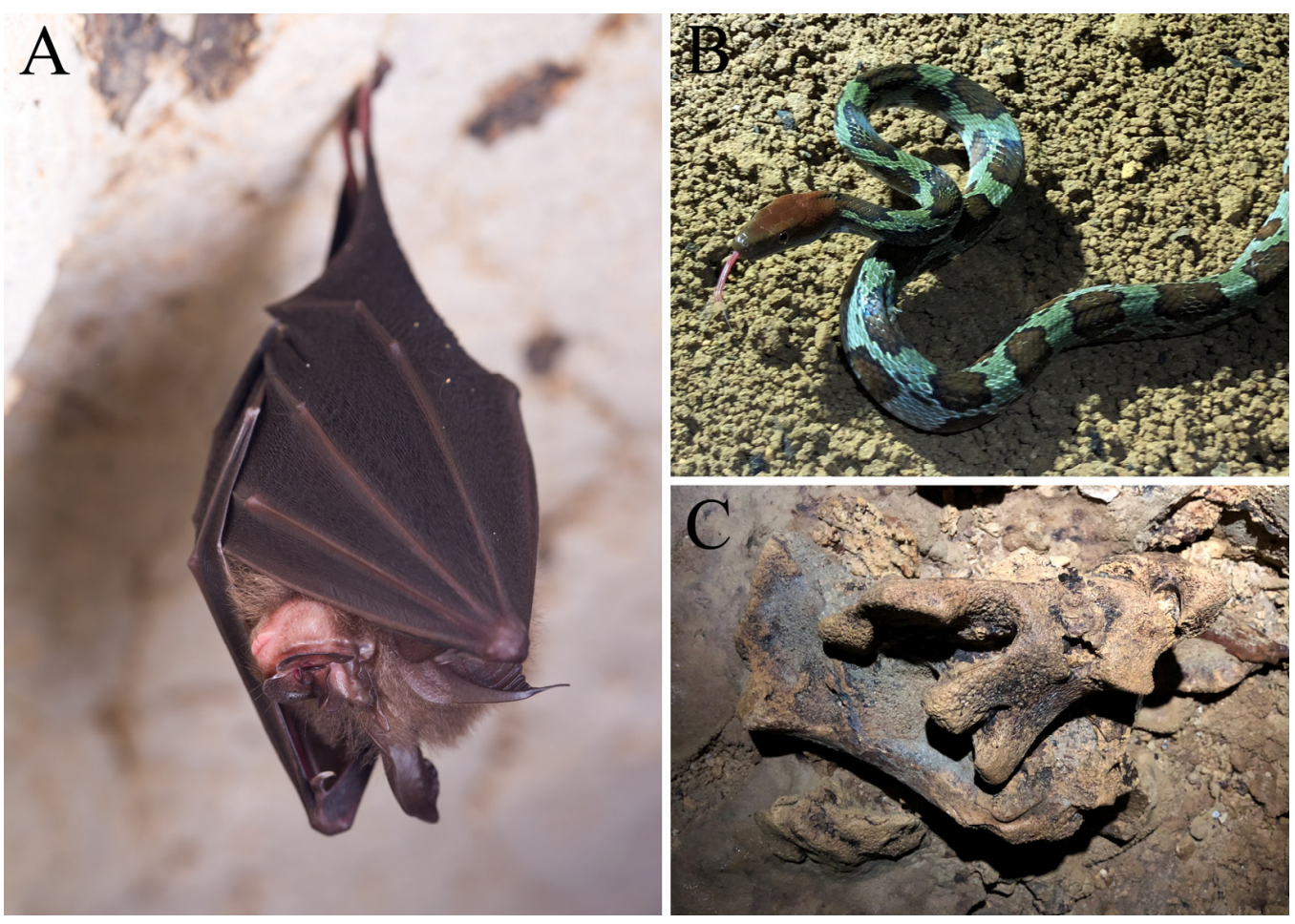

Figure 10. Other vertebrates in Ganxiao Dong. (A) Rhinolophus pearsonii Horsfield, 1851; (B) Elaphe moellendorffi (Boettger, 1886); (C) Fossil of Stegodon sp.

The beautiful Colubridae Elaphe moellendorffi (Boettger, 1886) (Figure 10B), frequent in Chinese caves, may prey upon bats, but its impact on their presence or abundance is unknown.

Bones of a fossil Stegodon were also found in the innermost part of the eastern branch of the cave (Figure 10C). The genus Stegodon is a very large size extinct mammal genus of the family Stegodontidae, order Proboscidea (elephants).

\section{Discussion}

The species richness of Ganxiao Dong is relatively low compared with several other temperate or tropical hot spots, but slightly above that of most of species-rich caves listed for continental Southeast Asia [22]. This, however, does not reflect a real biological pattern for two reasons. The first one is that the study of cave invertebrates in China is much more recent than in Europe or northern America, as illustrated by accumulation curves of taxa descriptions [19], and even more recent than that of several caves of Southeast Asia. The second reason is that multitaxa sampling in caves of China began only very recently compared to most regions which include subterranean diversity hotspots. The first multitaxa inventory of a Chinese cave is probably that of Feihu Dong in Hunan province, done in 1995 [23], but this kind of investigation really started in 2005 with a World Bank GEF project that included a karst biodiversity component focused on the Mulun karst. 
Not surprisingly, the 26 invertebrate species listed above are therefore only a part of the cave-adapted animals occurring in Ganxiao Dong. Many cave-restricted invertebrates, such as mites, pseudoscorpions, diplurans or ant-loving beetles (Pselaphinae), that are known from other nearby caves in the Maolan-Mulun karst, have not been observed in Ganxiao Dong during our surveys. Moreover, aquatic fauna, which is, in many caves of the world, richer than terrestrial fauna, has not been sampled (with the exception of isopods).

At present, 150 cave species have been found in the Huanjiang World Heritage Site of South China Karst [3] and more than 40 caves have been biologically surveyed to various extents in the Mulun karst [24,25]. Apart from Ganxiao Dong, several caves in Mulun also have a promising species richness. For example, 21 troglobionts have been found in Mashan Dong, as well as 13 troglobionts and 3 troglophiles in Dongzai Dong [22]. Outside the Mulun karst, Ji Dong has 14 troglobionts [24], including three sympatric species of troglobitic ground beetles.

Candidate caves for "hotspot" label are also from other karstic regions of China, in particular Feihu Fong and Shuanghe Dong, both situated more to the north. In the cave of Feihu Dong from the Huoyan karst (northwestern Hunan), 21 troglobiotic species or morphospecies have been recorded so far [23]. In Shuanghe Dong, the longest cave system in China which is over $300 \mathrm{~km}$ at present (Jean Bottazzi, pers. comm.), over 50 species were found from several caves, but none of them held more than 20 cave species (unpublished data).

In short, the cave Ganxiao Dong, together with Mashan Dong and Feihu Dong, harbours the richest cave fauna in China according, but several other caves, less intensively sampled, are likely to reach similar levels of richness. The sampling gaps underlined above, combined with the fast pace of discoveries of new taxa in the region, lead us to foresee a significant increase in species richness for the near future in South China caves and karsts.

All the species inventories mentioned above have the same limitation, i.e., undersampling of aquatic fauna and several terrestrial groups. Taking these biases into account, Ganxiao Dong and Feihu Dong would often compare favourably with most other tropical or temperate cave systems $[22,23,26]$.

The number of troglobiotic species measures the frequency of adaptations to cave life in a fauna. It does not inform about the impact of cave life on troglobiont biology and morphology. In this last respect, cave-obligate terrestrial species of southern China are at the front line, with exceptionally high level of troglomorphy in several major groups of cave invertebrates: millipedes, crickets and beetles $[8,27,28]$.

Author Contributions: Conceptualization, M.T., W.L. and S.H.; methodology, W.L., S.H. and H.W.; software, S.H. and W.L.; validation, L.D., A.B., M.T., W.L. and S.H.; formal analysis, S.H., L.D., M.T., W.L. and A.B.; investigation, M.T., G.W., H.W., S.H., L.D., A.B. and W.L.; resources, M.T., G.W. and H.W.; data curation, M.T., L.D., A.B., W.L. and S.H.; writing-original draft preparation, S.H., W.L. and M.T.; writing—review and editing, L.D., S.H., A.B., M.T. and W.L.; visualization, S.H., L.D., A.B., M.T. and W.L.; supervision, M.T., L.D. and W.L.; project administration, M.T., W.L. and G.W.; funding acquisition, M.T., L.D., W.L. and G.W. All authors have read and agreed to the published version of the manuscript.

Funding: This work was funded by the Protection Centre of Huanjiang World Natural Heritage and the National Natural Science Foundation of China, grant numbers 41871039 and 31801956 . Field sampling was supported until 2012 by a World Bank GEF linked to the project "Guangxi integrated forestry development and conservation".

Institutional Review Board Statement: Not applicable.

Informed Consent Statement: Not applicable.

Data Availability Statement: The data presented in this study is available in the cited references. 
Acknowledgments: We would like to thank the following colleagues who provided help to identify the cave animals: Guchun Zhou (Gannan Normal College, Ganzhou) and Huiming Chen (Institute of Biology, Guizhou Academy of Sciences, Guiyang) for spiders, Libiao Zhang (Institute of Zoology, Guangdong Academy of Sciences, Guangzhou) for the bat, Feng Zhang (Nanjing Agricultural University) for springtails, Stefano Taiti (Istituto per lo Studio degli Ecosistemi, Firenze) and Zhihong Xue (Guangdong Agricultural Academy of Sciences, Guangzhou) for isopods, Zhixiao Liu (Jishou University, Jishou) for the leech, Haomiao Zhang (Kunming Institute of Zoology, Chinese Academy of Sciences) for the dragonfly and Qidi Zhu (Hebei University, Baoding) for crickets.

Conflicts of Interest: The authors declare no conflict of interest.

\section{References}

1. Deharveng, L.; Brehier, F.; Bedos, A.; Tian, M.Y.; Li, Y.B.; Zhang, F.; Qin, W.G.; Tan, X.F. Mulun and surrounding karsts (Guangxi) host the richest cave fauna of China. Subterr. Biol. 2008, 6, 75-79.

2. Tian, M.Y.; Deharveng, L.; Bedos, A.; Li, Y.B.; Xue, Z.H.; Feng, B.; Wei, G.F. Advances of cave biodiversity survey: Result based mainly on invertebrates. In Proceedings of the 17th National Conference of Speleology, Tongshan, China, 1-3 November 2011; pp. 149-163.

3. Tian, M.Y.; Wei, G.F. (Eds.) Life in Dark World: Cavernicolous Creatures in Huanjiang World Heritage Site of South China Karst; Guangxi Science \& Technology Publishing House: Nanning, China, 2017; p. 136.

4. Liu, Z.Q.; Xiong, K.N.; Li, G.C.; Xiao, S.Z.; Wang, L.Y.; Wang, H.S.; Luo, D. Geomorphologic value and contributions of the Huanjiang Karst Extension to South China Karst World Heritage. Carsologica Sin. 2014, 33, 64-76.

5. Hu, F.; Dum, H.; Zeng, F.P.; Song, T.Q.; Peng, W.X.; Zhang, F. Dynamics of soil nutrient content and microbial diversity following vegetation restoration in a typical karst peak-cluster depression landscape. Acta Ecol. Sin. 2018, 38, 2170-2179.

6. Loksa, I. Einige neue Diplopoden-und Chilopodenarten aus chinesischen Höhlen. Acta Zool. Acad. Sci. Hung. 1960, 6, 137-148.

7. Liu, W.X.; Golovatch, S.I.; Wesener, T.; Tian, M.Y. Convergent evolution of unique morphological adaptations to a subterranean environment in cave millipedes (Diplopoda). PLoS ONE 2017, 12, e0170717. [CrossRef] [PubMed]

8. Golovatch, S.I.; Liu, W.X. Diversity, distribution patterns, and fauno-genesis of the millipedes (Diplopoda) of mainland China. ZooKeys 2020, 930, 153-198. [CrossRef] [PubMed]

9. Taiti, S.; Xue, Z.H. The cavernicolous genus Trogloniscus nomen novum, with descriptions of four new species from Southern China (Crustacea, Oniscidea, Styloniscidae). Trop. Zool. 2012, 25, 183-209. [CrossRef]

10. Tian, M.Y.; Huang, S.B.; Wang, X.H.; Tang, M.R. Contributions to the knowledge of subterranean trechine beetles in southern China's karsts: Five new genera (Insecta, Coleoptera, Carabidae, Trechinae). ZooKeys 2016, 564, 121-156. [CrossRef] [PubMed]

11. Uéno, S.-I.; Wang, F.X. Discovery of a highly specialized cave trechine (Carabidae: Trechinae) in southwest China. Elytra 1991, 19, 127-135.

12. Uéno, S.I.; Ran, J.C. Notes on Sinaphaenops (Coleoptera: Trechinae), with description of two new species. Elytra 1998, $26,51-59$.

13. Chen, J.J.; Tang, M.R.; Yang, P.J.; Tian, M.Y. Contribution to the knowledge of the aphaenopsian genus Sinaphaenops Uéno et Wang, 1991 (Coleoptera: Carabidae: Trechini). Zootaxa 2017, 4227, 106-118. [CrossRef] [PubMed]

14. Uéno, S.I. Two new genera and species of anophthalmic trechine beetles (Coleoptera, Trechinae) from limestone caves of southeastern Guizhou, South China. Elytra 1998, 26, 37-50.

15. Deuve, T. Nouveaux Trechidae cavernicoles chinois, découverts dans les confins karstiques du Sichuan, du Hubei et du Yunnan (Coleoptera, Adephaga). Rev. Française D'entomologie 1999, 21, 151-161.

16. Schiner, J.R. Fauna der Adelsberger-, Lueger- und Magdalenen Grotte. In Die Grotten und Höhlen von Adelsberg, Lueg, Planina und Laas; Schmidl, A., Ed.; Braumuller: Vienna, Austria, 1854; pp. 231-272.

17. Sket, B. Can we agree on an ecological classification of subterranean animals? J. Nat. Hist. 2008, 42, 1549-1563. [CrossRef]

18. Huang, T.; Liu, Z.; Gong, X.; Wu, T.; Liu, H.; Deng, J.; Zhang, Y.; Peng, Q.; Zhang, L.; Liu, Z. Vampire in the darkness: A new genus and species of land leech exclusively bloodsucking cave-dwelling bats from China (Hirudinda: Arhynchobdellida: Haemadipsidae). Zootaxa 2019, 4560, 257-272. [CrossRef] [PubMed]

19. Deharveng, L.; Bedos, A. Diversity of terrestrial invertebrates in subterranean habitats. In Cave Ecology; Moldovan, O.T., Kovác, L., Halse, S., Eds.; Springer: Cham, Switzerland, 2018; pp. 107-172.

20. Li, X.Z.; Niu, C.Y.; Huang, Q.Y.; Lei, C.L.; Stanley, D.W. Life cycle of Chetoneura shennonggongensis (Diptera: Keroplatidae: Keroplatinae) from Jiangxi Province, China. Insect Sci. 2009, 16, 351-359. [CrossRef]

21. Nishikawa, M. New records of Micronemadus pusillimus (Coleoptera, Cholevidae) from Malaysia and Indonesia. Kanagawa-Chuho 1989, 90, 158-160.

22. Deharveng, L.; Bedos, A. Biodiversity in the tropics. In Encyclopedia of Caves, 3rd ed.; White, W.B., Culver, D.C., Pipan, T., Eds.; Academic Press: Waltham, MA, USA, 2019; pp. 146-162.

23. Deharveng, L.; Bedos, A. The cave fauna of southeast Asia. Origin, evolution, and ecology. In Subterranean Ecosystems; Wilken, H., Culver, D.C., Humphreys, W.F., Eds.; Elsevier: Amsterdam, The Netherlands, 2000; pp. 603-632. 
24. Deharveng, L.; Tian, M.Y. Guangxi Integrated Forestry Development and Biodiversity Conservation Project. In Final Report on Subterranean Biodiversity of Guangxi Karsts and Natural Reserves Prepared for the Provincial Forestry Bureau of Guangxi; Provincial Forestry Bureau of Guangxi: Nanning, China, 2012; Annexes 34; p. 44.

25. Chen, J.J. Survey of Cave Biodiversity in Huanjiang World Heritage Site of South China Karst. Master's Thesis, South China Agricultural University, Guangzhou, China, 2017.

26. Culver, D.C.; Sket, B. Hotspots of subterranean biodiversity in caves and wells. J. Cave Karst Stud. 2000, 62, 11-17.

27. Latella, L. Biodiversity: China. In Encyclopedia of Caves, 3rd ed.; White, W.B., Culver, D.C., Pipan, T., Eds.; Academic Press: Waltham, MA, USA, 2019; pp. 127-135.

28. Faille, A. Beetles. In Encyclopedia of Caves, 3rd ed.; White, W.B., Culver, D.C., Pipan, T., Eds.; Academic Press: Waltham, MA, USA, 2019; pp. 102-108. 